\title{
MATLAB Application for the Selection of the Best Pipe Series/Parallel Arrangement in Piping Network
}

\author{
Ehab Hussein Bani-Hani \\ Australian College of Kuwait \\ Safat \\ West Meshrif
}

\begin{abstract}
The aim of this work is to show the application of computer software to solve complicated real life engineering problems. The software used is MATLAB where a code is written after the theoretical derivation of the governing equations. The application of MATLAB is on mechanical engineering fluid mechanics unit. The application is for the selection of the best arrangement of pipes series/parallel of different diameters, roughness, and lengths to achieve the best operating conditions for a pump in a specified pipe network. This includes selecting the minimum pump power and pressure drop. A MATLAB code is used to solve for different scenarios of arrangement which will save time and efforts.
\end{abstract}

Results from MATLAB shows a simple solution of simultaneously nonlinear equations describing the system compared to other traditional methods of solution like trial and error manual solutions. MATLAB makes the selection of a scenario among seven possible scenarios easy and accurate.

\section{Keywords}

MATLAB, pipe network, series, parallel, power, fluid mechanics.

\section{INTRODUCTION}

We Engineers use pumps to deliver a liquid to a specific location at a required rate. A pump is used to change the elevation, velocity, or pressure of a fluid. In nature, a fluid will flow naturally from a high place to a low place (like a waterfall) or from a high pressure to a low pressure. When a fluid is needed uphill from a source like a lake or pond, at higher pressure than a source, or at a higher rate, a pump is considered to accomplish the task. Where fluid flow rate can be calculated as follows:

$Q=\frac{V}{t}$

Where $V$ is the volume (usually $\mathrm{m}^{3}$ ) and $\mathrm{t}$ is the time (usually in s) which makes the volume flow rate measured ion $\mathrm{m}^{3} / \mathrm{sec}$. However, the volume flow rate can be measured by dividing a known amount of liquid in a container over the time it took to fill it (as per our Eq.1), or by the multiplication of the velocity of the flow $(v, \mathrm{~m} / \mathrm{s})$ by the cross-sectional area of the opening the fluid is coming out $\left(\mathrm{A}, \mathrm{m}^{2}\right)$. That is also the flow rate, as shown in Eq. (2)

$Q=v A$

To characterize the piping network, Bernoulli equation is applied between two points. The two points are connected by pipe or pipe network, where the conditions are known. Generally, between two surfaces of reservoirs where the total head at point 1 must be equal with the total head at point 2 Fig. 1. Adjusted for any increase in head due to pumps, major losses due to pipe friction and minor losses due to entries, exits, fittings, etc. Pump head developed is generally a function of the flow through the system Eq.(3) shown below [1].

$\frac{P_{1}}{\rho g}+\propto_{1} \frac{v_{1}^{2}}{2 g}+z_{1}+h_{p}=\frac{P_{2}}{\rho g}+\propto_{2} \frac{v_{2}^{2}}{2 g}+z_{2}+h_{T}+$

$h_{L}$ major $+h_{L}$ minor

Where:

$\mathrm{P}_{1}, \mathrm{P}_{2}$ are pressures at points 1 and 2 respectively, $\mathrm{Pa}, \mathrm{z}_{1}, \mathrm{z}_{2}$ are elevation from same reference line at points 1 , and 2 respectively, $\mathrm{m}, v_{1}, v_{2}$ are velocity at points 1 and 2 respectively, $\mathrm{m} / \mathrm{s}, \mathrm{h}_{\mathrm{p}}$ is the pump head, $\mathrm{m}, \mathrm{h}_{\mathrm{T}}$ is the Turbine Head, $m, h_{L}$ major is the losses due to friction, $m, h_{L}$ minor is the losses due to fittings, $\mathrm{m}, \alpha$ is the coefficient of loss due to sudden expansion or contraction, $\mathrm{g}$ is the gravitational acceleration, $9.81 \mathrm{~m} / \mathrm{sec}^{2}$

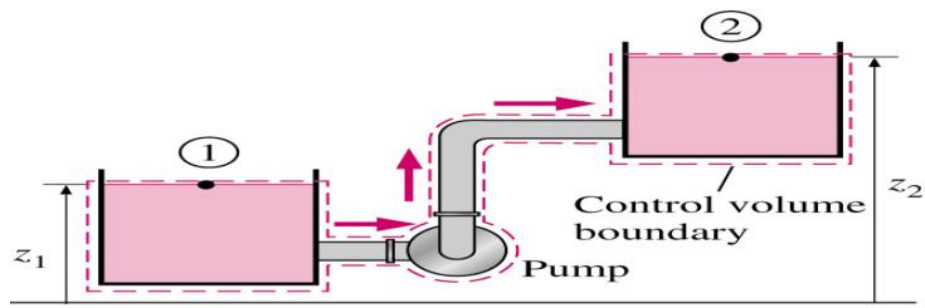

Fig 1: two points where Bernoulli principle is applied, [1]

Engineering applications for piping systems could be as simple as a single pipe conveying a fluid from one reservoir to another or as complicated as a system of interconnected pipes forming a large distribution network [2]. In modeling such large networks, optimal demand allocation is necessary in order to prevent the network topology from getting too complicated and the network modeling from being too cumbersome [3,2] and other applications like psychometric charts [4].

\section{THEORITICAL ANALYSIS}

\subsection{Friction Losses in Pipes}

Friction losses are a complex function of the system geometry, the fluid properties and the flow rate in the system. The head loss is roughly proportional to the square of the flow rate in most engineering flows (fully developed, turbulent pipe flow). This observation leads to the Darcy-Weisbach [1] equation for head loss due to friction:

$h_{L}$ major $=\sum f \frac{L}{D} \frac{v_{a v g}{ }^{2}}{2 g}$

Where $f$ is the friction coefficient, $\mathrm{D}$ pipe diameter, $\mathrm{L}$ is the pipe length, and $v_{a v g}$ is the average velocity in the pipe. Although it is often count for a major portion of the head loss, especially in process piping, the additional losses due to entries and exits, fittings and valves are traditionally referred 
to as minor losses. The minor losses are any head loss present in addition to the head loss for the same length of straight pipe. Similar to pipe friction, these losses are roughly proportional to the square of the flow rate. Defining $\mathrm{K}$, the loss coefficient, by:

$h_{L}$ minor $=\sum K \frac{v_{a v g}{ }^{2}}{2 g}$

\subsection{Friction factor}

The friction factor $\boldsymbol{f}$ depends on many factors such as the velocity of the flow and the pipe roughness. It can be estimated either by using charts like Moody chart or by equations. The selection of the equation to calculate the friction coefficient is important, that is it determines the complexity of solution method by selecting implicit or explicit equations. To avoid the iterative solution of the ColebrookWhite equation, many explicit formulas have been proposed in the literature for a simpler evaluation of the pipe friction factor [5]. For example Eq.(6) as follows:

$f=\frac{0.25}{\left[\log \left(\frac{\varepsilon}{3.7 D}+\frac{5.74}{R e^{0.9}}\right)\right]^{2}}$

Where Re is Reynolds Number that is the fundamental dimensionless group in viscous flow used to characterizing the flow as laminar or turbulent. It is defined in terms of velocity, length, pipe diameter, and kinematic viscosity as shown in Eq.(7).

$R e=\frac{\rho v D}{\mu}$

Thus in this work, the following case study will be investigated: Water is to be pumped from tank 1 to tank 2 which is at $30 \mathrm{~m}$ higher. Both tanks are opened to atmosphere. A single pump is to be used in the piping system to pump 85 $\mathrm{L} / \mathrm{s}$ with three pipes. The specifications of the pipes are summarized in table 1 . There are two scenarios regarding the distance between the two tanks. Case one when the distance between the two tanks is ranging from 300 to $375 \mathrm{~m}$, and in case two when the distance between the two tanks is ranging from 600 to $675 \mathrm{~m}$. it is required to select the pump to transfer the fluid which is water with the minimum pumping power. The power required depends on the pipes number, pipes specifications, and pipe arrangement (series/parallel) to create the pipe network.

Table 1. Pipes Specifications to be used in different pipe arrangements to create a pipe network for minimum pumping power.

\begin{tabular}{|c|c|c|c|}
\hline Pipe & Diameter $(\mathbf{m m})$ & $\begin{array}{c}\text { Length } \\
(\mathbf{m})\end{array}$ & $\begin{array}{c}\text { Roughness } \\
\boldsymbol{\varepsilon}(\mathbf{m m})\end{array}$ \\
\hline $\mathbf{1}$ & 150 & 300 & 0.3 \\
\hline $\mathbf{2}$ & 125 & 330 & 0.15 \\
\hline $\mathbf{3}$ & 100 & 360 & 1.5 \\
\hline
\end{tabular}

Despite that many solution procedures are available in the literature for such types of piping systems [6,7]. MATLAB as modern mathematical tools can be integrated into the solution to handle the problematic steps. It may serve as a tool to solve problems relevant to fluid flow such as viscous flow phenomena [8].

\section{PROPOSED SOLUTION}

In this work MATLAB will used. However, literature shows different procedures and methods to solve the equation [9] where trial and error solution to solve complicated systems is used. In literature recent study [10] showed a numerical procedure for modeling branching pipes which would eliminate the need for a trial-and-error approach.

\subsection{Solution for case one}

If the distance between the two tanks is ranging from 300 $375 \mathrm{~m}$
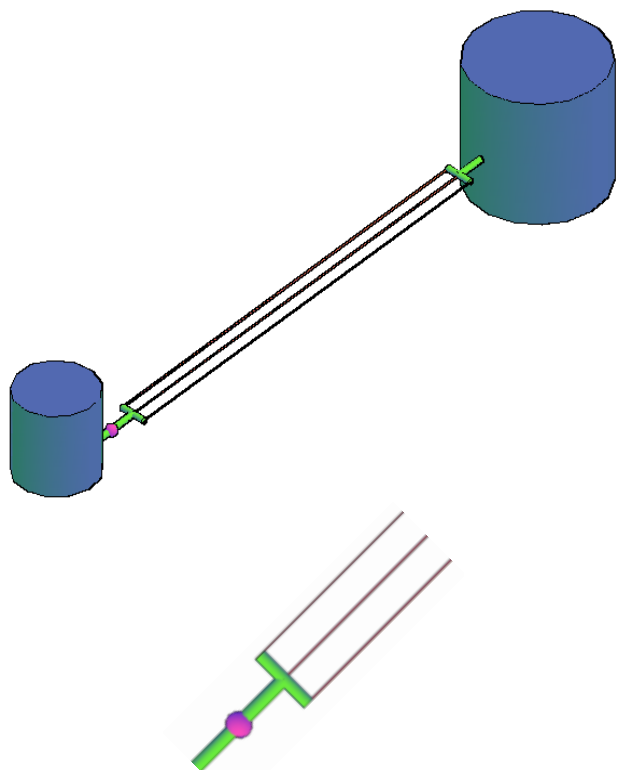

Fig 2: Three pipes in parallel

\subsubsection{Assumptions:}

- From the Continuity Balance equation: $\mathrm{Q}_{\text {in }}=\mathrm{Q}_{\text {out }}$ (steady state)

- $\quad$ Neglecting the Minor Losses: $h_{L}$ minor $=0$

- Pipes in green colors (connections) are neglected in calculations

\subsubsection{Given dato}

Water density, $\rho_{\text {water }}=999.6 \mathrm{~kg} / \mathrm{m}^{3}$, water viscosity, $\mu=$ $1.307 \times 10^{-3} \mathrm{~kg} / \mathrm{m} . \mathrm{s}$, total volume flow rate, $\mathrm{Q}_{\mathrm{T}}=85 \times 10^{-3}$ $\mathrm{m}^{3} / \mathrm{s}$. this data should be used to calculate the pipes diameters, lengths, and roughness $\varepsilon$.

this simplifies Bernoulli equation as follows:

$$
\frac{p / 1}{\rho g}+\alpha_{1} \frac{v / \frac{1}{2 g}}{2 g}+z_{1}+h_{p}=\frac{p / 2}{p g}+\alpha_{2} \frac{v z_{2}^{2}}{2 g}+z_{2}+h_{T}+h_{L} \text { major }+h_{L} m \text { mor }
$$

The pump head

$h_{p}=z_{2}-z_{1}+h_{L} m$

$h_{p}=30+h_{L} m$

Total volume flow rate

$Q_{T}=Q_{1}+Q_{2}+Q_{3}$

$Q_{1}=85 \times 10^{-3}-Q_{2}-Q_{3}$ 
The velocity

$v_{1}=\frac{4}{3.14} \frac{Q_{1}}{D_{1}^{2}}$

$Q_{2}=\frac{3.14}{4} D_{2}^{2} v_{2}, Q_{3}=\frac{3.14}{4} D_{3}^{2} v_{3}$

The head loss calculations

$h_{L 1}=f_{1} \frac{L_{1}}{D_{1}} \frac{v_{1}^{2}}{2 g}, h_{L 1}=f_{1} \frac{L_{1}}{D_{1}} \frac{v_{1}^{2}}{19.62}$

Since $h_{L 1}=h_{L 2}=h_{L 3}=h_{L} m \quad$ (Parallel Pipes)

$h_{L 1}=f_{2} \frac{L_{2}}{D_{2}} \frac{v_{2}^{2}}{2 g}=f_{3} \frac{L_{3}}{D_{3}} \frac{v_{3}^{2}}{2 g}$

$v_{2}=\left[\frac{19.62 h_{L 1} D_{2}}{f_{2} L_{2}}\right]^{1 / 2}, v_{3}=\left[\frac{19.62 h_{L 1} D_{3}}{f_{3} L_{3}}\right]^{1 / 2}$

Friction coefficient

$f_{1}=\frac{0.25}{\left[\log \left(\frac{\varepsilon_{1}}{3.7 D_{1}}+\frac{5.74}{R e_{1}} e^{0.9}\right)\right]^{2}}, f_{2}=\frac{0.25}{\left[\log \left(\frac{\varepsilon_{2}}{3.7 D_{2}}+\frac{5.74}{R e_{2}}{ }^{0.9}\right)\right]^{2}}$

$f_{3}=\frac{0.25}{\left[\log \left(\frac{\varepsilon_{3}}{3.7 D_{3}}+\frac{5.74}{R e_{3} 0.9}\right)\right]^{2}}$

For Reynolds number calculations

$R e_{1}=\frac{\rho v_{1} D_{1}}{\mu}$ where $R e_{1}=764804.8967 v_{1} D_{1}, R e_{2}=$

$\frac{\rho v_{2} D_{2}}{\mu}$ where $R e_{2}=764804.8967 v_{2} D_{2}, R e_{3}=\frac{\rho v_{3} D_{3}}{\mu}$

where $R e_{3}=764804.8967 v_{3} D_{3}$

The Power $\quad N_{\min }=Q_{T} \Delta P$

Where $\Delta P=\rho g h_{P}$

$N_{\text {min }}=833.51646 h_{P}$

\subsubsection{Mat lab Results}

The procedure is repeated for seven possible pipe arrangements in the pipe network. Using MATLAB will make it easy to get the results.

Table 2. Comparison between all 7 possible scenarios for proposed solution number 1

\begin{tabular}{|c|c|c|c|}
\hline Scenarios & $\begin{array}{c}\text { Minimum } \\
\text { Power } \\
(\mathbf{W})\end{array}$ & $\begin{array}{c}\text { Pipe } \\
\text { Network }\end{array}$ & Remarks \\
\hline $\mathbf{1}$ & $7.1093 \times 10^{4}$ & Pipe 1 & $\begin{array}{c}\text { Pipe is used } \\
\text { for the } \\
\text { whole } \\
\text { distance }\end{array}$ \\
\hline $\mathbf{2}$ & $1.3562 \times 10^{5}$ & Pipe 2 & - \\
\hline $\mathbf{3}$ & $8.0844 \times 10^{5}$ & Pipe 3 & - \\
\hline $\mathbf{4}$ & $4.2027 \times 10^{4}$ & $\begin{array}{c}\text { Pipes 1 \& 2 } \\
\text { (Parallel) }\end{array}$ & $\begin{array}{l}\text { Parallel } \\
\text { Pipes }\end{array}$ \\
\hline
\end{tabular}

\begin{tabular}{|c|c|c|c|}
\hline $\mathbf{5}$ & $5.4857 \times 10^{4}$ & $\begin{array}{c}\text { Pipes 1 \& 3 } \\
\text { (Parallel) }\end{array}$ & - \\
\hline $\mathbf{6}$ & $0.8345 \times 10^{5}$ & $\begin{array}{c}\text { Pipes 2 \& 3 } \\
\text { (Parallel) }\end{array}$ & - \\
\hline $\mathbf{7}$ & $3.7935 \times 10^{4}$ & $\begin{array}{c}\text { Pipes 1, 2 \& } \\
\text { 3 (Parallel) }\end{array}$ & $\begin{array}{c}\text { The Best } \\
\text { Selection }\end{array}$ \\
\hline
\end{tabular}

From the previous table, it has been noticed the scenario number seven has the minimum power.

\subsection{Solution for case two}

If the distance between the two tanks is ranging from 600-675 $\mathrm{m}$

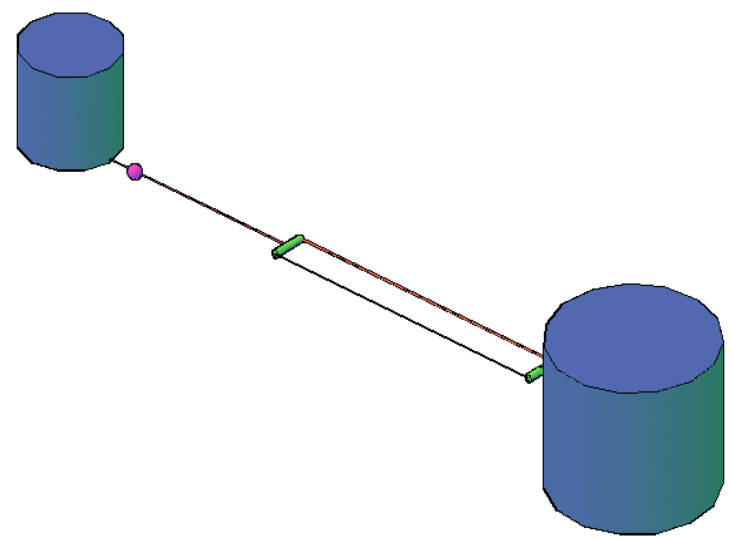

Fig 3: Two pipes in parallel with the third one in series

The same data and conditions as in solution number 1 are applied here with difference in the distance between the two tanks. The distance is longer so three pipes can not be used in parallel. Instead two pipes are in parallel and one is in series. The challenge to select which one is in series depends on the scenario in table 3 .

\subsubsection{MATLAB Results}

Table 3. Comparison between all 6 possible scenarios for proposed solution number 2

\begin{tabular}{|c|c|c|c|}
\hline Scenarios & $\begin{array}{c}\text { Minimum } \\
\text { Power } \\
(\mathbf{W})\end{array}$ & Pipe Network & Remarks \\
\hline $\mathbf{1}$ & $1.8171 \times 10^{5}$ & $\begin{array}{c}\text { Pipes 1 \& 2 } \\
\text { (Series) }\end{array}$ & - \\
\hline $\mathbf{2}$ & $8.5453 \times 10^{5}$ & $\begin{array}{c}\text { Pipes 1 \& 3 } \\
\text { (Series) }\end{array}$ & - \\
\hline $\mathbf{3}$ & - & $\begin{array}{c}\text { Pipes 2 \& 3 } \\
\text { (Series) }\end{array}$ & $\begin{array}{c}\text { Applicable } \\
\text { (Out of } \\
\text { Range) }\end{array}$ \\
\hline $\mathbf{4}$ & - & $\begin{array}{c}\text { Pipe 2 in Series } \\
\text { Pipes 1 \& 3 } \\
\text { parallel }\end{array}$ & $\begin{array}{c}\text { Applicable } \\
\text { (Out of } \\
\text { Range) }\end{array}$ \\
\hline
\end{tabular}




\begin{tabular}{|c|c|c|c|}
\hline 5 & - & $\begin{array}{c}\text { Pipe 3 in Series } \\
\text { Pipes 1 \& 2 } \\
\text { parallel }\end{array}$ & $\begin{array}{c}\text { Not } \\
\text { Applicable } \\
\text { (Out of } \\
\text { Range) }\end{array}$ \\
\hline $\mathbf{6}$ & $1.2954 \times 10^{5}$ & $\begin{array}{c}\text { Pipe 1 in Series } \\
\text { Pipes 2 \& 3 in p } \\
\text { parallel }\end{array}$ & The Best \\
\hline
\end{tabular}

From the previews table, it has been observed that the arrangement number 6 has the minimum pumping power.

\section{CONCLUSION}

In conclusion, it has been clarified that when designing piping network to deliver a fluid (a liquid) from one tank to another at higher level, a pump can be such a solution to implement that. From Engineering point of view, the most considerable criteria that should be focused on, is how to deliver this fluid with less pumping power. Bernoulli principal is one of the efficient ways to do that, since it considers many criteria such that: major losses (friction factor, length and diameter of the pipe) and minor losses (Fittings, elbows and exits and entries). Moreover, the design of the piping networks itself whether they are in parallel or in series. Finally, it has been noticed that the MATLAB is one of the useful programs that help engineers to solve designing problems accurately with less paper work and time.

For having many pipes with different specifications makes it sometimes difficult to select the best in terms less friction and pressure drop as well as pumping power to arrange them as series and parallel or both to create piping network. To test the possible scenarios means repeating calculations many times. As shown in this work there are nine equations with nine unknowns. These equations must be solved simultaneously with high degree of non linearity that shown in evaluating the friction coefficient. Take into consideration a small values of the pipe roughness the system of equations may be stiff system. Thus MATLAB is an ideal solution to similar cases where one can select the best arrangement to achieve a target. Finally, the problem can be studied from another point of view such as selecting the best pipe material (roughness of the pipe from other side) to minimize the pumping power. In addition to the complexity by selecting the equation for friction coefficient, all what is required is to write the equation in MATLAB m-file to solve regardless of the forms used of the equation. Thus whatever the case MATLAB can achieve quick and accurate solution in comparison with manual or other software.

\section{REFERENCES}

[1] Cengel, Y. A., and Cimbala, M. J., Fluid Mechanics fundamentals and applications, Mc Graw Hill, Second Edition, pp. 345-374. 2010.

[2] Wahba, E. M., An Improved Computational Algorithm for Teaching Hydraulics of Branching Pipes in Engineering Curricula, Computer Applications in Engineering Education. 10, 2015.

[3] Farina, G., Creaco, E., and Franchini, M., Using EPANET for modelling water distribution systems with users along the pipes, Civ Eng Environ Syst 31, 2014, pp. 36-50.

[4] Gupta, P. K. and Patel, R. N. 2017. A teaching-learning tool for elementary psychrometric processes on psychrometric chart using MATLAB. Comput Appl Eng Educ.

[5] Brkić, D., Review of explicit approximations to the Colebrook relation for flow friction, J Petrol Sci Eng 77 ,2011, pp. 34-48.

[6] Avesani, D., Righetti, M., Righetti, D., and Bertola, P., The extension of EPANET source code to simulate unsteady flow in water distribution networks with variable head tanks, J Hydroinform 14, 2012, pp. 960973.

[7] Todini, E., Extending the global gradient algorithm to unsteady flow extended period simulations of water distribution systems, J Hydroinform 13 no. 2, 2011, pp. 167-180.

[8] Çetin, B., Özturk, Y., Taze, S., Viscous Fluid Flow Calculations for Undergraduate Fluid Mechanics Education Using MATLAB, Ulusal Is1 Bilimi ve Tekni!i conference, September, 2011, Zonguldak.

[9] Hodge, B., K., and Taylor, R., P., Analysis and Design of Energy Systems, Pearson Education, Third Edition, pp. 72-113. 1999.

[10] Haktanır, T., and Ardıçlıŏlu, M., Numerical modeling of Darcy-Weisbach friction factor and branching pipes problem, Adv Eng Softw 35, 2004, pp. 773-79. 